\title{
POLISSEMIA NA GRAMÁTICA DE CONSTRUÇÕES: UMA ANÁLISE A PARTIR DA CONSTRUÇÃO TRANSITIVA
}

Nedja Lima de Lucena*

(iD) http://orcid.org/0000-0002-9412-8771

Como citar este artigo: LUCENA, N. L. de. Polissemia na Gramática de Construções: uma análise a partir da construção transitiva. Todas as Letras - Revista de Língua e Literatura, São Paulo, v. 23, n. 2, p. 1-12, maio/ago. 2021. DOI 10.5935/1980-6914/ eLETLL2113259

Submissão: abril de 2020. Aceite: janeiro de 2021.

Resumo: Com base no quadro teórico da Linguística Funcional Centrada no Uso e na Gramática de Construções, este artigo analisa um tipo de relação de herança, os elos de polissemia, em tokens da construção transitiva. A partir do exame de dados empíricos, discute que os falantes estendem o significado básico dessa construção, que se atrela a uma cena transitiva prototípica, para abarcar outros tipos de eventos que se afastam do protótipo. Desse modo, a forma é pareada com sentidos diversos, evidenciando polissemia construcional.

Palavras-chave: Linguística Funcional Centrada no Uso. Gramática de Construções. Construção transitiva. Relações de herança. Polissemia.

\section{CONSIDERAÇõES INICIAIS}

Uma língua sem polissemia seria realmente um sistema não só excessivamente pesado, com um número incomensuravelmente superior de formas, como inevitavelmente estático, funcional apenas num mundo sem variação nem inovação. A polissemia é, pois, uma realidade natural, conceptual e linguisticamente necessária (SILVA, 2006, p. 1). 
A noção de construção ${ }^{1}$, tal como entendida neste trabalho, está presente em vários estudos linguísticos, como se pode ver em Lakoff (1987), Fillmore (1988) e Fillmore, Kay e O'Connor (1988) ${ }^{2}$. No entanto, essa noção se ampliou e ganhou ênfase a partir do programa de pesquisa proposto por Goldberg $(1995,2006)$, Croft (2001), Tomasello (1998, 2003, 2005), Bybee (2010), Traugott e Trousdale (2013), inter alia.

No Brasil, a última década se mostra frutífera em relação às pesquisas que se somam à abordagem construcional: um número considerável de publicações, teses e dissertações indicam como essa abordagem tem respaldado estudos de descrição das línguas naturais.

Várias são as perspectivas que assumem a construção como centro de análise (cf. TRAUGOTT; TROUSDALE, 2013). Tais perspectivas compartilham a noção de que as construções - emparelhamentos convencionalizados de forma e significado - devem ser tomadas como as unidades primárias da língua. Considerando que não há fronteiras nítidas entre léxico e gramática, reconhece-se que as construções formam um continuum, "partindo de elementos muito específicos, como o item lexical janela ou a expressão idiomática esquentar a cabeça, até padrões mais abstratos como a categoria adjetivo ou a construção transitiva" (FERRARI, 2011, p. 129).

Diante desse fértil contexto de investigação linguística, o presente artigo discute um tipo de construção do português, caracterizada por ser superordenada, esquemática e produtiva: a construção transitiva (cf. LUCENA, 2018; FURTADO DA CUNHA; SILVA, 2018; LOPES, 2019). Reflete-se aqui sobre os elos de polissemia que diferentes tokens (ocorrências/instâncias) dessa construção sinalizam. Em outras palavras, observa-se como a forma da construção é recrutada para dar conta de diferentes sentidos ${ }^{3}$, tomados neste trabalho como um tipo de relação de herança por polissemia (GOLDBERG, 1995).

Com relação à forma, a construção transitiva (doravante, CT) possui moldura sintática que se configura a partir de dois argumentos em torno de um verbo, sendo que tais argumentos assinalam as relações gramaticais de sujeito e de objeto direto. Quanto à função, essa moldura está estreitamente associada a um sentido central que compreende alguém agir intencionalmente a fim de causar uma mudança numa entidade paciente (SLOBIN, 1982). Assim, a CT incorpora um esquema $\left[\mathrm{X}_{\text {agente }} \mathrm{VERBO}_{\text {ação-processo }} \mathrm{Y}_{\text {afetado }}\right]$, conforme se observa nas seguintes amostras:

(1) [Ele] cobriu lá o corpo né (Corpus D\&G, Fala, p. 27).

(2) [O gato] pulou dentro e rasgou o pai dele todinho (Corpus D\&G, Fala, p. 28).

(3) Já mataram alguns turistas ali (Corpus D\&G, Fala, p. 123).

As ocorrências (1-3) caracterizam-se, em termos sintáticos, por apresentarem sujeito ( $\varnothing$ = ele; o gato; eles), verbo (cobriu; rasgou; mataram) e objeto direto

1 O termo construção é utilizado pela própria gramática tradicional para se referir a fenômenos como construção passiva, reflexiva e impessoal. O termo também faz parte da história do gerativismo, no entanto, com outro significado. Nessa abordagem, a construção estava relacionada a regras específicas da gramática transformacional, bem como servia de pano de fundo para se pensar em princípios gerais (SALOMÃO; MIRANDA, 2009).

2 A expressão gramática de construção foi cunhada por Fillmore, Kay e O'Connor (1988).

3 Adianto que nas abordagens construcionistas não há uma distinção entre significado codificado (semântico-lexical) e significado contextual (pragmático) (cf. FRIED, 2015). Ressalto que, embora tenha consciência da distinção entre os termos significado e sentido nos estudos semânticos (OLIVEIRA, 2001), esses são tomados aqui como sinônimos. 
(o corpo; o pai; alguns turistas). Semanticamente, denotam uma mudança de uma entidade, que é paciente da ação verbal: um corpo que passa de descoberto para coberto; o pai que tem partes do corpo rasgadas; e alguns turistas que passam do estado de vivos para mortos, respectivamente. Essas amostras possuem em comum o fato de que todas referem uma mudança de estado numa entidade, provocada por um agente através de uma ação, sentido prototípico associado à CT.

No entanto, há casos que se afastam desse significado prototípico, evidenciando outros sentidos relacionados a tipos de eventos distintos, como se verá ao longo deste trabalho. São, pois, os sentidos de tokens da CT que este estudo intenta observar em dados empíricos, coletados de corpora diversos do português brasileiro ${ }^{4}$.

A pesquisa está assentada no quadro teórico da Linguística Funcional Centrada no Uso (LFCU), uma tradução brasileira para Usage-Based Linguistics, que se configura como uma perspectiva resultante do diálogo teórico e empírico entre funcionalismo e cognitivismo (TOMASELLO, 1998, 2003) ${ }^{5}$. Um axioma básico dessa proposta teórica figura na ideia de que o conhecimento, seja linguístico ou não, é governado por processos cognitivos de domínio geral, por isso não é necessário diferenciar conhecimento linguístico de conhecimento não linguístico (BYBEE, 2010; CROFT; CRUSE, 2004).

Ancorada nesse quadro teórico, para fins de análise, adota-se o paradigma da Gramática de Construções de inspiração em Goldberg (1995, 2006) e a concepção de protótipos tal como tratada por Taylor (2003).

Em termos metodológicos, a pesquisa é de natureza quali-quantitativa, ou seja, busca interpretar os dados com base no referencial teórico adotado, tendo como suporte dados quantitativos que possam ser somados à compreensão do fenômeno descrito (MINAYO, 2001). Observando textos orais e escritos do português brasileiro, foram selecionadas 1.440 orações cujo padrão sintático conforma-se ao da CT: orações formadas pela configuração Sujeito (S) - Verbo (V) e Objeto Direto (OD).

O presente texto está organizado do seguinte modo, a partir desta seção introdutória: na seção seguinte, são delineados os principais pressupostos teóricos da LFCU, com foco na perspectiva da Gramática de Construções; posteriormente, é tecida a discussão sobre a CT e seus elos de polissemia; por último, são apresentadas as considerações finais e as referências norteadoras.

\section{Linguística Funcional Centrada no Uso: Gramática de Construções}

O proficuo diálogo entre a linguística funcional norte-americana e a linguística cognitiva motivou o surgimento da agenda teórica Usage-Based Linguistics, assumida aqui como Linguística Funcional Centrada no Uso (LFCU), expressão adotada por Martelotta (2011) e ampliada por Cezario e Furtado da Cunha (2013).

De maneira geral, funcionalistas e cognitivistas assumem alguns pressupostos básicos que fornecem as bases para a LFCU, tais como: a objeção à ideia de

4 Furtado da Cunha (1998), Furtado da Cunha (2011), revista IstoÉ, blogs Vida Materna e Santa Dieta, contos literários "As mãos do meu filho" (VERÍSSIMO, 1981) e "Passeio noturno" (FONSECA, 1975).

5 Em alguns trabalhos, é possível encontrar o termo Linguística Cognitivo-Funcional para a tradução da expressão em inglês (Usage-Based Linguistics). 
autonomia da sintaxe; a concepção de que léxico e gramática formam um continuum, isto é, não há fronteiras nítidas entre esses; a adoção de fatores semântico-pragmáticos nas análises linguísticas; o entendimento de que a língua está fundamentada como um complexo mosaico de atividades cognitivas e sociocomunicativas; a compreensão de que as habilidades linguísticas podem ser tomadas e apreendidas da mesma forma que outras habilidades cognitivas; e ainda a ideia de que a língua consiste em um inventário de construções utilizadas na comunicação.

Nesse viés, na descrição das formas linguísticas é fulcral considerar o papel que a forma desempenha, ou seja, sua função. Consoante Bybee (2010), na LFCU, a gramática é assinalada como a representação cognitiva da experiência dos indivíduos com a língua; logo, o uso linguístico motiva sua estrutura. Por essa razão, a expressão linguística pode ser compreendida como uma pista para rastrear o mosaico cognitivo complexo subjacente a ela. De acordo com essa perspectiva, falante e ouvinte estão no cerne da construção do significado e negociam as significações nas práticas sociodiscursivas; assim, o tratamento dado à estrutura linguística não pode estar dissociado do significado.

A LFCU se interessa, em especial, pela investigação da construção gramatical, que pode ser traduzida como um pareamento convencionalizado de forma e significado (ou função), conforme defende Goldberg $(1995,2006)$. Dito de outro modo, a construção é um esquema geral e simbólico, isto é, são abstrações que "se instanciam no uso linguístico por meio de ocorrências específicas, os construtos. Logo, uma construção é uma generalização com base em construtos do mesmo tipo", afirmam Furtado da Cunha e Lacerda (2017, p. 20).

No polo da forma de uma construção, conjugam-se aspectos fonológicos, morfológicos e sintáticos; no polo do significado, estão as propriedades semânticas, pragmáticas e discursivo-funcionais. O significado da construção pode ser entendido como aspectos convencionalizados da função dessa construção, o que inclui não somente propriedades da situação descrita pela interação, mas também propriedades do discurso no qual essa interação é baseada. Sendo assim, a forma e o significado convencional da construção são internos a ela, de maneira que esse par é vinculado mediante um elo de correspondência simbólica. Assim, os parâmetros da forma linguística não são apartados do significado, mas motivados ou prediziveis das bases dele. Além disso, a relação entre a função e a forma não é totalmente previsivel, nem completamente arbitrária, ao passo que não pode ser interpretada necessariamente como a soma das partes que compõem a construção (GOLDBERG, 1995; CROFT, 2001).

Goldberg (2006) e Bybee (2006) assinalam que a frequência tem papel fundamental no estabelecimento de uma construção. Isso ocorre porque os falantes, ao se depararem com um novo uso linguístico, exploram os recursos que lhes são acessiveis, conformando tal uso a uma construção, que, por sua vez, se torna uma unidade de processamento.

Além do mais, as construções podem ser organizadas em redes e concebidas como esquemas cognitivos do mesmo tipo dos que existem em outros domínios da cognição. Traugott e Trousdale (2013, p. 1) resumem essa ideia ao afirmarem que as construções "são unidades em que algum aspecto do signo é tão idiossincrático (GOLDBERG, 1995) ou tão frequente (GOLDBERG, 2006) que o signo é armazenado como um par forma-significado na mente do falante". 
No caso das construções oracionais simples há um vínculo entre suas estruturas semânticas e cenas básicas da experiência humana, o que Goldberg (1995) vai intitular de hipótese de codificação da cena (scene encoding hypotheses), por exemplo, movimento, transferência, causação, posse, estado ou mudança de estado. Assim, uma cena transitiva prototípica envolve necessariamente uma cena básica de transferência. Nesse ínterim, evoco as discussões empreendidas em Givón (2001), Goldberg (1995, 2006), Lucena (2018), Furtado da Cunha e Silva (2018) e Lopes (2019) para ressaltar que a CT remete à codificação de um evento em que um participante intencionalmente age para causar um afetamento ou efetuamento de um participante paciente. Langacker (2008) e Talmy (1988) explicam que o primeiro participante direciona um fluxo de energia que é transmitido e causa alguma mudança, seja de condição, de estado ou de localização, no segundo, que é impactado por essa energia, como se observa nos casos (1-3) e em:

(4) Ele apalpa o topo da minha barriga e nisso leva um tapa na mão, coitado (desculpe Dr. Carlos!) (blog Vida materna, 6 nov. 2012).

Na ocorrência (4), ele, referindo-se ao médico e codificado sintaticamente como S, pratica volicionalmente ação de apalpar, que provoca uma mudança transitória no segundo elemento (o topo da minha barriga), codificado sintaticamente como OD. Observe que ocorre uma mudança de estado temporária do topo da barriga enquanto esta é tateada, ou seja, é direcionado um fluxo de energia do médico $\rightarrow$ topo da barriga da paciente.

À luz do referencial teórico, assumo que esse perfil sintático-semântico reflete o protótipo de uma oração transitiva. De um lado, há o reflexo de uma transferência completa da ação de uma entidade para outra, causando alguma modificação, ainda que transitória, no estado desta. De outro, há uma moldura sintática que se estabelece em $\left[X_{\text {agente }} V E R B O_{\text {ação-processo }} Y_{\text {afetado }}\right]$. A amostra (4), ao realçar uma cena básica de transferência, ilustra a hipótese de codificação da cena levantada por Goldberg (1995).

As construções oracionais (ou construções de estrutura argumental) interagem com os verbos e os papéis semânticos dos argumentos que este evoca. As construções têm papéis argumentais que se associam ao conjunto de papéis semânticos do verbo, como agente, paciente, tema, recipiente, locativo, entre outros. Sob esse viés, cada sentido de um verbo é associado com um frame semântico que, de certo modo, elenca certos papéis participantes: o número e o tipo de slot ${ }^{6}$ que se relacionam ao significado de um determinado verbo.

A forma e a interpretação geral do padrão oracional básico de uma língua são motivadas pela semântica e/ou informação sintática especificada pelo verbo principal. Para Adele Goldberg, os verbos podem aparecer com um arranjo diversificado de configurações argumentais, como é o caso de slice (fatiar/partir) em He sliced the bread (construção transitiva), Pat sliced the carrots into the salad (construção de movimento causado) e Pat sliced Chris a piece of pie (construção ditransitiva).

Goldberg (1995) afirma que a CT é interpretada como aquela em que ocorrem dois tipos de macropapéis: protoagente e protopaciente, que possuem proprieda-

6 Posição argumental. 
des que se associam sintaticamente com o $\mathrm{S}$ e com o OD, respectivamente. $\mathrm{Ob}$ serve o quadro a seguir:

Quadro 1 - Propriedades de protoagente e protopaciente

\begin{tabular}{|c|c|}
\hline Protoagente & Protopaciente \\
\hline $\begin{array}{c}\text { Envolvimento volicional no evento } \\
\text { ou estado }\end{array}$ & Sofre mudança de estado \\
\hline $\begin{array}{c}\text { Senciência e/ou percepção } \\
\text { Causa um evento ou mudança de estado } \\
\text { em outro participante }\end{array}$ & \begin{tabular}{c} 
Tema ampliado \\
\hline $\begin{array}{c}\text { Movimento (relativo à posição de outro } \\
\text { participante) }\end{array}$
\end{tabular} \\
$\begin{array}{c}\text { Estaticidade (relativa afo movimento } \\
\text { participante }\end{array}$ \\
\hline $\begin{array}{c}\text { Existe independentro participante) } \\
\text { nomeado pelo verbo }\end{array}$ \\
\hline
\end{tabular}

Fonte: Goldberg (1995, p. 116).

No caso da CT, Goldberg defende a importância do princípio de seleção de argumento, que diz respeito a como essas propriedades se delineiam em termos de $\mathrm{S}$ e $\mathrm{OD}$, de maneira que o argumento que evoca mais propriedades do protoagente é instanciado como S; aquele que abarca mais propriedades de protopaciente é tomado como OD. Tais propriedades podem ser relacionadas ao esqueleto da CT, permitindo que outras construções sejam herdadas da dela, bem como licenciando um vasto arranjo de tokens que se agrupam à $\mathrm{CT}^{7}$.

Os tokens de uma construção, chamados de construtos por Traugott e Trousdale (2013), relacionam-se de vários modos. Para Goldberg (1995, p. 78-79), existem relações de herança que ocorrem por polissemia, subpartes, instanciação e extensão metafórica. Interessa aqui apontar como a polissemia pode ser vista nas ocorrências da CT.

A relação de herança por polissemia compreende as ligações semânticas entre uma construção e suas extensões. Ora, nesse aspecto, é fulcral assinalar que a polissemia é entendida como uma rede de sentidos flexiveis, de impossivel distinção precisa, adaptáveis ao contexto e abertos à mudança, conforme advoga Silva (2006). Explica esse autor que a agenda cognitivista entende o significado como dinâmico e "configurado como um feixe de conhecimentos" (p. 59), e ao mesmo tempo é encarnado nos interesses e nas experiências sociocomunicativas dos indivíduos.

A CT detém um significado abstrato muito geral relacionado ao evento transitivo prototípico. A partir disso, diversas extensões do protótipo licenciam um vasto arranjo de instanciações transitivas, como será delineado na seção seguinte. Nesse sentido, as línguas diferem em como e por que estendem os significados da CT para expressar cenas transitivas não prototípicas. 


\section{RELAÇÕES DE HERANÇA EM TOKENS DA CONSTRUÇÃO TRANSITIVA}

A CT é uma construção que ocorre em várias línguas e, no caso do português brasileiro, sua configuração pode ser representada pelo seguinte esquema:

Figura 1 - Esquema da CT

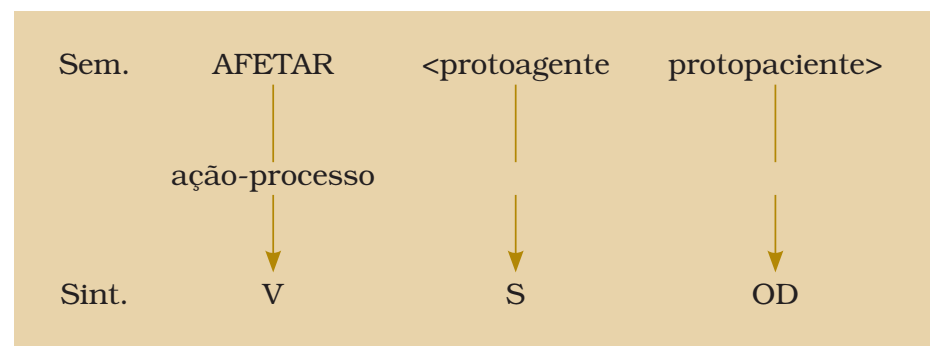

Fonte: Elaborada pela autora.

O esquema denota a configuração sintática SVO, ordem canônica do português brasileiro, ao passo que aponta para o significado de causar uma mudança de estado, condição ou localização numa entidade paciente. Assim, do ponto de vista sintático, existe um $\mathrm{S}$ e um $\mathrm{OD}$, sendo que o primeiro comporta o traço semântico de [+] agentividade, enquanto o segundo de [+] afetamento. $O$ verbo de tipo semântico ação-processo (cf. BORBA, 1996) implica em sua moldura um agente e um paciente, ou seja, a moldura do verbo é análoga ao padrão construcional, como se observa nas ocorrências (1-4) e na seguinte:

(5) D. Margarida tira os sapatos que lhe apertam os pés (conto "As mãos do meu filho").

Na ocorrência (5), nota-se um caso típico de transferência, em que uma entidade agente ( $D$. Margarida) - humano e animado - intencionalmente afeta (ação expressa por tirar) e causa uma mudança de estado da entidade paciente (os sapatos) que é deslocado dos pés para outro lugar.

A CT pode ser usada para codificar diversas cenas que não necessariamente são prototípicas. Isso significa que os tipos semânticos de verbos são variáveis, pois a CT recruta esses tipos verbais, bem como os slots podem ser preenchidos por uma variedade de elementos que paulatinamente se afastam do protótipo, na medida em que o traço de [+] agentividade e [+] afetamento se diluem nas ocorrências:

(6) Fizemos um levantamento, que mostrei ao Conselho Federal de Medicina, com mais de dez casos de mortes e complicações graves atribuídas a cirurgiões plásticos (revista IstoÉ, 11 jul. 2012).

(7) Ficou todo mundo estendido na ... na ... na ... lá na BR ... na pista ... e passou algumas pessoas e prestou socorro à gente né [...] e a empregada e o motorista sofreu só escoriações leves né ... foram medicados e liberados né (Corpus D\&G, Fala, p. 22). 
(8) All I have to give... eu amo essa música... (Banco Conversacional de Natal, Conversa 4, p. 112)

(9) Eu tive uma gestação super tranquila, com os sintomas e incômodos clássicos e comuns a praticamente todas as gestantes (blog Vida materna, 19 nov. 2012).

(10) Ela só percebeu que eu ia para cima dela quando ouviu o som da borracha dos pneus batendo no meio-fio. Peguei a mulher acima dos joelhos, bem no meio das duas pernas, um pouco mais sobre a esquerda, um golpe perfeito [...] (conto "Passeio noturno").

Nas amostras (6) e (10) é possivel perceber o traço de [+] agentividade, vinculado ao S, bem como a mudança de estado ou condição do paciente: em (6), uma entidade (um levantamento) que não existia passa a existir; em (10), o paciente (a mulher) muda da condição de viva para morta, ou seja, ambos os pacientes carregam o traço de [+] afetamento.

Na ocorrência (7), a mudança de condição sucede na entidade codificada como S (a empregada e o motorista) que não é agente da ação verbal, e sim, paciente. O verbo (sofrer) denota um processo (cf. BORBA, 1996), S possui traço de [-] agentividade e o elemento OD (escoriações leves) carrega o traço de [-] afetamento.

Nos casos (8) e (9), a ideia de transferência ou mudança de estado sequer se entrevê no contexto: na amostra (8), há uma ação (sentir) que é perceptual/cognitiva em que o referente do $\mathrm{S}$ experiencia esse sentir, logo, o traço de [+] agentividade não se apresenta aqui. Ao mesmo tempo, essa música, estímulo do sentir possui traço de [-] afetamento. Em (9), ocorre a descrição de um estado, de forma que a entidade codificada sintaticamente como S não é agentiva, nem o OD representa [+] afetamento.

As ocorrências (7), (8) e (9) são mais periféricas em relação ao exemplar prototípico. Nota-se que o verbo pode evidenciar um processo (sofrer), uma ação perceptual (amar) e até mesmo um estado (ter). Ao mesmo tempo, em todas as ocorrências listadas até aqui, os slots são preenchidos com elementos cujos traços de agentividade e afetamento podem ser vistos em termos de grau, sendo uns [+/-] agentes e outros [+/-] pacientes. Em todas as amostras evidenciadas, o padrão sintático é o mesmo, havendo flexibilidade no significado.

Nas amostras selecionadas nesta pesquisa, observou-se a seguinte distribuição de tipos semânticos de verbos.

Tabela 1 - Distribuição de tipos semânticos de verbos nos corpora

\begin{tabular}{|c|c|}
\hline Tipo verbal & Número/percentual \\
\hline Ação-processo & $770(53,5 \%)$ \\
\hline Ação & $335(23,3 \%)$ \\
\hline Estado & $181(12,5 \%)$ \\
\hline Processo & $154(10,7 \%)$ \\
\hline Total & $1.440(100 \%)$ \\
\hline
\end{tabular}

Fonte: Elaborada pela autora. 
As amostras analisadas conformam-se à estrutura sintática da CT (forma) e denotam significados que variam do mais próximo ao prototípico, como nas amostras com verbos de ação-processo e nos casos mais periféricos, que denotam processos e estados.

Goldberg (1995) afirma que a ideia de agentividade e afetamento é uma contribuição da semântica da CT e não apenas do verbo. O fato de a semântica lexical do verbo (como é o de ação-processo) ser icônica à da CT facilita a configuração, mas não a determina. Isso explica o fato de verbos como sofrer, amar ou ter serem recrutados para a CT. A autora justifica essa afirmação ao defender que, na abordagem construcional, sentidos implausíveis para o verbo são evitados, bem como há a preservação da composicionalidade da expressão: não é o item lexical em si que carrega o sentido, mas sua integração à construção.

Além do mais, no caso da CT, pode-se afirmar que suas ocorrências assinalam um continuum com casos mais ou menos próximos ao exemplar prototípico. Relacionando isso aos verbos, proponho a figura a seguir para ilustrar que há um sentido básico, central, e outros que se diluem no continuum:

Figura 2 - Relação de verbos e CT

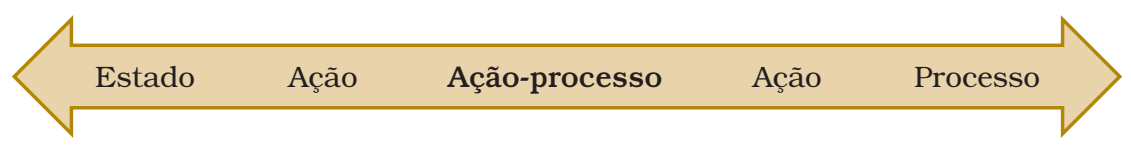

Fonte: Elaborada pela autora.

Goldberg $(1995,2006)$ explica que cada construção exibe uma estrutura prototípica e está associada a uma família de sentidos intimamente vinculados. Quando isso acontece, pode-se dizer que é um caso de polissemia construcional, ou seja, a mesma forma é pareada com sentidos distintos que se relacionam, como ocorre na construção aqui examinada. Nesse caso, o usuário da língua estende o sentido da CT, relacionado ao evento transitivo prototípico que envolve a ideia de [+] agentividade e [+] afetamento da entidade codificada como $\mathrm{S}$ e $\mathrm{OD}$, respectivamente, para casos que são mais periféricos. Em outras palavras, o exemplar prototípico, com propriedades mais concretas da experiência, serve de alicerce para experiências mais abstratas; assim, do sentido básico da CT emanam os demais.

Desse modo, a CT tem seu sentido estendido de várias maneiras e permite ao falante utilizar e interpretar o padrão básico (familiar) em diversos contextos. De acordo com Bybee (2010), o usuário da língua elege um padrão construcional que é associado a uma ocorrência correspondente ao sentido básico desse padrão, ou seja, um membro prototípico. A frequência de uso desse padrão fornece ao usuário da língua generalizações que podem ser estendidas para outros membros. Isso porque, ao se deparar com um uso novo, o usuário, por economia, tende a recuperar uma representação armazenada em sua memória e associá-la a um item novo, como acontece com os novos sentidos da CT emanados do sentido mais prototípico. 


\section{Considerações Finais}

O presente trabalho evidenciou aspectos da polissemia construcional da CT à luz da LFCU. Na abordagem construcional, a polissemia está relacionada a uma forma que se vincula a diversos sentidos. No caso da CT, a moldura sintática é preservada, ao passo que a moldura semântica abarca sentidos vários, desde aquele mais prototípico, que envolve [+] agentividade e [+] afetamento de uma entidade na posição de S e OD, respectivamente, até aqueles que se afastam do protótipo, como os casos em que a ideia de afetamento sequer se entrevê no contexto. Isso ocorre porque a frequência de uso de um dado padrão, como acontece com ocorrências com verbos de ação-processo, permite ao usuário da língua, ao se deparar com um novo uso (como estados e processos), associá-lo a uma representação já arquivada na cognição.

\section{POLYSEMY IN THE CONSTRUCTION GRAMMAR: AN ANALYSIS FROM TRANSITIVE CONSTRUCTION}

Abstract: Based on the theoretical framework of Usage-Based Linguistics and in the Construction Grammar, this paper analyzes a type of inheritance relationship, the polysemy links, in tokens of the transitive construction. The examination of empirical data argues that speakers extend the basic meaning of this construction, which is linked to a prototypical transitive scene, to cover other types of events that depart from the prototype. Thus, the shape is paired with different meanings, showing constructional polysemy.

Keywords: Usage-Based Linguistics. Construction Grammar. Transitive construction. Inheritance relations. Polysemy.

\section{REFERÊNCIAS}

BORBA, F. S. Uma gramática de valências para o português. São Paulo: Ática, 1996.

BYBEE, J. Frequency of use and the organization of language. Oxford: Oxford University Press, 2006.

BYBEE, J. Language, usage and cognition. Cambridge: Cambridge University Press, 2010.

CEZARIO, M. M.; FURTADO DA CUNHA, M. A. (org.). Linguística centrada no uso: uma homenagem a Mário Martelotta. Rio de Janeiro: Mauad X: Faperj, 2013.

CROFT, W. Radical construction grammar: syntactic theory in typological perspective. Oxford: Oxford University Press, 2001.

CROFT, W.; CRUSE, A. Cognitive linguistics. Cambridge: Cambridge University Press, 2004.

FERRARI, L. Introdução à linguística cognitiva. São Paulo: Contexto, 2011.

FILLMORE, C. On grammatical construction. California: UCB, 1988. 
FILLMORE, C.; KAY, P.; O'CONNOR, C. Regularity and idiomaticity in Grammatical Constructions: the case of let alone. Language, n. 64, p. 501-538, 1988. FONSECA, R. Feliz ano novo. Rio de Janeiro: Nova Fronteira, 1975.

FRIED, M. Construction grammar. In: ALEXIADOU, A.; KISS, T. (ed.) Handbook of linguistics and communication science. Berlin: Mouton de Gruyter, 2015. p. 974-1003.

FURTADO DA CUNHA, M. A. (org.). Corpus Discurso \& Gramática: a língua falada e escrita na cidade do Natal. Natal: EDUFRN, 1998.

FURTADO DA CUNHA, M. A. (org.). Banco Conversacional de Natal. Natal: EDUFRN, 2011.

FURTADO DA CUNHA, M. A.; LACERDA, P. F. A. C. Gramática de construções: princípios básicos e contribuições. In: OLIVEIRA, M. R.; CEZARIO, M. M. (org.). Funcionalismo linguístico: diálogos e vertentes. Niterói: Eduff, 2017. p. 17-46.

FURTADO DA CUNHA, M. A.; SILVA, J. R. Transitividade: do verbo à construção. Revista Linguística, v. 14, n. 1, p. 48-64, 2018.

GIVÓN, T. Syntax. Amsterdam: John Benjamins, 2001. v. 1.

GOLDBERG, A. E. A construction grammar approach to argument structure. Chicago: University of Chicago Press, 1995.

GOLDBERG, A. E. Constructions at work: the nature of generalization in language. Oxford: Oxford University Press, 2006.

ISTOÉ. São Paulo: Três, edição 2226, ano 36, 11 jul. 2012.

LAKOFF, G. Women, fire and dangerous things: what categories reveal about mind. Chicago: University of Chicago Press, 1987.

LANGACKER, R. Cognitive grammar. a basic introduction. Oxford: Oxford University Press, 2008.

LOPES, M. G. A construção transitiva prototípica e a construção transitiva causativa no português: um caso de variação construcional? Diadorim, Rio de Janeiro, v. 21, n. 2, p. 99-124, 2019.

LUCENA, N. L. A construção transitiva no português brasileiro: aspectos cognitivo-interacionais. Revista Linguística, v. 14, n. 1, p. 65-82, 2018.

MARTELOTTA, M. Mudança linguística: uma abordagem baseada no uso. São Paulo: Cortez, 2011.

MINAYO, M. C. S. (org.). Pesquisa social: teoria, método e criatividade. 18. ed. Petrópolis: Vozes, 2001.

OLIVEIRA, R. P. Semântica. In: MUSSALIM, F.; BENTES, A. C. (org.). Introdução à lingüística: domínios e fronteiras. 1. ed. São Paulo: Cortez, 2001. 2 v., p. 23-54. SALOMÃO, M. M.; MIRANDA, N. (org.). Construções do português do Brasil: da gramática ao discurso. Belo Horizonte: EDUFMG, 2009.

SILVA, A. S. O mundo dos sentidos em português: polissemia, semântica e cognição. Coimbra: Almedina, 2006.

SLOBIN, D. The origins of grammatical encoding of events. In: HOPPER, P. (ed.). Syntax and semantics. New York: Academic Press, 1982. 15 v., p. 409-422.

TALMY, L. Force dynamics in language and cognition. Cognitive Science, Berkeley, v. 12, p. 49-100, 1988. 
TAYLOR, J. Linguistic categorization. Oxford: Oxford University Press, 2003. TOMASELLO, M. (ed.). The new psychology of language cognitive and functional approaches to language structures. New Jersey: Lawrence Erlbaum, 1998. 1 v. TOMASELLO, M. (ed.). The new psychology of language cognitive and functional approaches to language structures. New Jersey: Lawrence Erlbaum, 2003. 2 v. TOMASELLO, M. Constructing a language: a Usage-Based Theory of Language Acquisition. Cambridge: Harvard University Press, 2005.

TRAUGOTT, E.; TROUSDALE, G. Constructionalization and constructional changes. Oxford: Oxford University Press, 2013.

VERÍSSIMO, E. Outros contos (1942/1959). 6. ed. Porto Alegre: Globo, 1981.

VIDA MATERNA. Gestação e parto. Disponivel em: http://www.vidamaterna.com/. Acesso em: 24 nov. 2015. 